\title{
Clinical and radiological characteristics of central pulmonary adenocarcinoma: a comparison with central squamous cell carcinoma and small cell lung cancer and the impact on treatment response
}

This article was published in the following Dove Press journal:

OncoTargets and Therapy

\section{Zhe Wang ${ }^{1,2}$ \\ Minghuan $\mathrm{Li}^{2}$ \\ Yong Huang ${ }^{3}$ \\ $\mathrm{Li} \mathrm{Ma}{ }^{3}$ \\ Hui Zhu ${ }^{2}$ \\ Li Kong ${ }^{2}$ \\ Jinming $\mathrm{Yu}^{2}$}

'School of Medicine, Shandong University, Jinan, Shandong, China; ${ }^{2}$ Department of Radiation Oncology, Shandong Cancer Hospital Affiliated to Shandong University, Jinan, Shandong, China; ${ }^{3}$ Department of Radiology, Shandong Cancer Hospital Affiliated to Shandong University, Jinan, Shandong, China
Correspondence: Jinming Yu

Department of Radiation Oncology, Shandong Cancer Hospital Affiliated to Shandong University, Jinan, Shandong 250I I7, China

Tel +8653167626971

Fax +8653 I 87984079

Email sdyujinming@।63.com

Yong Huang

Department of Radiology, Shandong Cancer Hospital Affiliated to Shandong University, Jinan, Shandong 250 I 17, China

Tel +8653167626971

Fax +8653187984079

Email huangyong|970888@sina.com
Purpose: The proportion of central pulmonary adenocarcinoma (ADC) in central-type lung cancer has been gradually increasing due to the overall increasing incidence of pulmonary ADC. But the clinical and radiological characteristics of central ADCs remain unclear. In this study, we compared the clinical and radiological characteristics of central ADCs with those of small cell lung cancers (SCLCs) and squamous cell carcinomas (SQCCs) and investigated the impact of these characteristics on patients' treatment response.

Patients and methods: The medical records of 302 consecutive patients with central lung cancer from July 2014 to September 2016 were retrospectively reviewed. There were 99 patients with ADC, 95 with SQCC and 108 with SCLC. Computed tomography images were interpreted by two radiologists. Treatment response was determined by Response Evaluation Criteria In Solid Tumors 1.1.

Results: Univariate analyses found that younger age, female sex, no history of smoking, higher levels of carcinoembryonic antigen (CEA), contralateral hilum lymphadenopathy, contralateral lung metastasis, pleural nodules and pleural metastasis to the interlobular fissure were significantly correlated with central ADC. Multivariate logistic regression analyses revealed that compared with central SQCC, female sex, younger age, no history of smoking, higher levels of CEA and contralateral hilum lymphadenopathy were the significantly independent indicators of central pulmonary ADC. Furthermore, compared with central SCLC, younger age, higher levels of CEA and cytokeratin 19 fragment (Cyfra21-1), lower levels of neuron-specific enolase, pleural nodules and lack of vascular involvement were significantly associated with central ADC. In 85 central ADC patients who received first-line platinum-based chemotherapy, both univariate and multivariate logistic regression analyses revealed that pulmonary emphysema had a negative correlation with treatment response (odds ratio $=8.04, p=0.02$ ).

Conclusion: Our study revealed that central pulmonary ADCs exhibited more aggressive clinical and radiological characteristics. Pulmonary emphysema was an independent and negative indicator for treatment response of central ADC.

Keywords: central-type lung cancer, clinical characteristic, CT characteristic, prognosis, pulmonary emphysema

\section{Introduction}

According to GLOBOCAN2012, lung cancer is the most common type of malignancy as well as the leading cause of cancer death worldwide. ${ }^{1}$ Lung cancers can be categorized as central type or peripheral type by the location of primary lesions. Lung cancers can also be classified as small cell lung cancer (SCLC) and non-small cell lung cancer 
(NSCLC), which can have significantly different prognosis and treatment strategies. Pulmonary adenocarcinoma (ADC) and squamous cell carcinoma (SQCC) are the most common pathologic types and account for $50 \%$ and $30 \%$ of NSCLC, respectively. ${ }^{2}$ According to the literature, the majority of patients with central lung cancer have SCLC and SQCC. However, the proportion of central pulmonary ADC in central-type lung cancer has been gradually increasing due to the overall increasing incidence of pulmonary ADC.

With the development of advanced technologies, multiple diagnostic tools are available for detecting lung cancer. Among the many available tools, computed tomography (CT) is the most practical for screening and diagnosis due to its high resolution, convenience for follow-up and high benefit-cost ratio. ${ }^{3,4}$ Also, recent studies have revealed that radiological features in $\mathrm{CT}$ play a critical role in inferring histologic subtypes, ${ }^{5-7}$ predicting treatment response ${ }^{8}$ and determining patients' prognosis, ${ }^{5,9-11}$ in addition to differentiating malignant disease or staging established malignance. There have been several studies on the radiological characteristics and prognoses of central SCLCs and SQCCs, ${ }^{5,12-15}$ whereas studies on central ADC are rare. Furthermore, several studies have demonstrated that regional lymph node metastases and prognosis of patients with central ADC are different from those of patients with peripheral ADC. ${ }^{16-19}$ The clinical and radiological characteristics of central ADCs and their impact on treatment response should be investigated to guide therapeutic strategies.

At present, there are no reports of the clinical and radiological characteristics of central ADCs. In this study, we compared the clinical and radiological features of central ADCs with those of central SQCCs and SCLCs. Moreover, we investigated the correlation between these features and the treatment response to first-line chemotherapy in patients with central ADC.

\section{Patients and methods}

\section{Patients}

This study was approved by the Institutional Review Board of Shandong Cancer Hospital, and all patients provided written informed consent for this study. We retrospectively reviewed the medical records of all patients with histologically confirmed primary lung cancer from July 2014 to September 2016. We selected patients who met the following criteria: 1) thoracic CT images acquired with our picture archiving and communication system before the patients received any treatment; 2) available clinical data including age, sex, smoking status, TNM stage (defined according to the eighth American Joint Committee on Cancer) and levels of tumor biomarkers (carcinoembryonic antigen [CEA], neuron-specific enolase [NSE] and cytokeratin 19 fragment [Cyfra21-1]); and 3) bronchoscopic findings or surgical resection, showing that the primary lesions were located in the region between the trachea and the segmental bronchi. There were 302 consecutive patients included in our study, comprising 99 patients with ADC, 95 patients with SQCC and 108 patients with SCLC. Of the 99 patients with central ADC, 7 underwent surgery, 7 received tyrosine kinase inhibitor and 85 received platinum-based chemotherapy with or without radiotherapy as the first-line therapy. Treatment response to first-line chemotherapy was determined by Response Evaluation Criteria In Solid Tumors 1.1. Also, patients were divided into response group (partial remission and complete remission) and nonresponse group (stable disease and progressive disease).

\section{CT image acquisition}

CT scans were performed on CT systems (SIEMENS Somatom Definition AS; Siemens Medical Systems, Erlangen, Germany) with the following parameters: collimation, $64 \times 0.6 \mathrm{~mm}$; beam pitch, 1.5 ; tube voltage, $120 \mathrm{kVp}$ and tube current, $200 \mathrm{mAs}$. The slice thickness of image reconstruction for lung parenchyma and mediastinum was $5 \mathrm{~mm}$. CT images were reviewed with a $20.8 \mathrm{in} .(52.8 \mathrm{~cm}), 2,048 \times 31,560$ pixel grayscale monitor (Coronis3MP; Barco Display Systems, Kortrijk, Belgium). The lung window settings were as follows: window width, 1,600 HU, and window level, $-600 \mathrm{HU}$. The mediastinal window settings were as follows: window width, $400 \mathrm{HU}$, and window level, $40 \mathrm{HU}$.

\section{Visual interpretation of CT images}

Two radiologists ( $\mathrm{YH}$ and LM with 24 and 17 years of experience, respectively) interpreted all $\mathrm{CT}$ images. Both radiologists were blinded to the pathologic types, and different opinions between the two radiologists were resolved by discussion until consensus was reached. Analysis of lung parenchyma was performed in accordance with the Fleischner Society Recommendations. ${ }^{20}$ Tumor size (transverse maximum diameter), location (left vs right), margins (spiculated, lobulated), as well as presence of air bronchogram, bronchovascular bundle convergence, pulmonary infarction, lymphangitic carcinomatosis, pulmonary emphysema, lymphadenopathy (mediastinum, contralateral hilum, ipsilateral hilum), contralateral lung metastasis, pleural effusion and vascular involvement were recorded. Pleural nodules were defined as nodules or incrassation of either 
side of pleura, except for the pleura of interlobular fissure. According to Shim et al, ${ }^{21}$ more than five fissural nodules or uneven fissural incrassation was indicative of interlobular fissure pleural metastasis.

\section{Statistical analysis}

Statistical analysis was performed using SPSS software (version 22.0). Comparison of proportions of the categorical data among pathologic types was analyzed by $\chi^{2}$ or Fisher's exact test if appropriate. We analyzed the distribution of continuous quantitative data by Kolmogorov-Smirnov test. Continuous quantitative data were all non-normally distributed and compared among patients by Kruskal-Wallis test in our study. The optimal cutoff value of CEA level discriminating ADC from non-ADC (SQCC and SCLC) was calculated by using a receiver operating characteristic curve. Multinomial logistic regression analysis was performed to identify independent indicative factors for pathologic types of central lung cancers, and of central ADC group was performed as baseline. Univariate and multivariate logistic regression models were used to evaluate the association between the radiological characteristics and the treatment response to first-line chemotherapy in patients with central ADC. Variables witha a $p$-value of $<0.1$ by univariate analysis were included in the multivariable model, which was adjusted for known predictive factors (sex, age, smoking status and tumor stage). A $p$-value of $<0.05$ was considered to be statistically significant, while a $p$-value of $<0.0167$ was considered to be statistically significant after Bonferroni correction.

\section{Results}

\section{Patient and demographic features}

There were 302 patients included in our study, with a median age of 61 years (range: $36-87$ ). The demographic features are presented in Table 1. Male patients $(\mathrm{n}=213,70.5 \%)$ and smokers $(n=184,60.9 \%)$ were predominant in our study. Also, most of the patients were at stage III or IV with the rates of $51.6 \%$ and $38.1 \%$, respectively. But in contrast to our previous understanding of central lung cancers, in our study, ADC ( $\mathrm{n}=99,32.8 \%)$ was as prevalent as $\mathrm{SQCC}(\mathrm{n}=95$, $31.4 \%)$ and SCLC ( $\mathrm{n}=108,35.8 \%)$.

\section{The association between clinical features and pathologic types}

The associations between clinical features and pathologic types are presented in Table 2 . Age $(p=0.005)$, sex ratio $(p<0.001)$ and smoking status $(p<0.001)$ were significantly different among ADC, SQCC and SCLC patients. Female
Table I Summary of demographic features of patients $(\mathrm{N}=302)$

\begin{tabular}{ll}
\hline Variables & $\mathbf{n}(\%)$ \\
\hline Age, median (range) & 6 I (36-87) \\
Sex & \\
$\quad$ Male & $213(70.5)$ \\
$\quad$ Female & $89(29.5)$ \\
Smoking status & \\
$\quad$ Smoker & $184(60.9)$ \\
Nonsmoker & $118(39.1)$ \\
Pathologic subtypes & \\
Adenocarcinoma & $99(32.8)$ \\
Squamous cell carcinoma & $95(31.4)$ \\
Small cell lung cancer & $108(35.8)$ \\
TNM stage & \\
I & $19(6.3)$ \\
II & $12(4.0)$ \\
III & $156(5 I .6)$ \\
IV & II $(38.1)$ \\
\hline
\end{tabular}

patients, younger patients and nonsmokers were more likely to have ADC rather than SQCC or SCLC. More importantly, the levels of CEA $(p<0.001)$, Cyfra21-1 $(p<0.001)$ and NSE $(p<0.001)$ also significantly differed among the three pathologic types. The levels of CEA were significantly higher in the central ADC group. The receiver operating characteristic analysis revealed that the area under the curve for CEA levels was 0.742 (95\% CI 0.675-0.810; Figure 1).

\section{The association between radiological characteristics and pathologic types}

As shown in Table 3, the majority of the morphologic characteristics on the $\mathrm{CT}$ images were significantly associated with the pathologic types, except for the location of primary lesion, presence of lobulated margin and ipsilateral hilum lymphadenopathy.

In contrast to non-ADC, ADC presented with more contralateral hilum lymphadenopathy ( $p<0.001)$, contralateral lung metastasis $(p<0.001)$, pleural nodules $(p<0.001)$ and interlobular fissure pleural metastasis $(p<0.001)$. Several representative CT images of central ADC are presented in Figure 2. Compared with NSCLC patients, SCLC patients had a larger mean maximal lesion size $(p=0.001)$. Besides, both the rates of vascular involvement and pulmonary infarction were significantly different between NSCLC and SCLC ( $p<0.001$ and $p<0.001$, respectively). Other significantly different radiological features among the three groups included the presence of spiculated margin $(p=0.04)$, air bronchogram $(p=0.02)$, bronchovascular bundle convergence ( $p=0.002$ ), lymphangitic carcinomatosis $(p=0.03)$, pulmonary emphysema $(p=0.007)$ and pleural effusion $(p<0.001)$. 
Table 2 Associations between clinical features and pathologic types

\begin{tabular}{|c|c|c|c|c|c|c|c|}
\hline Characteristics & ADC, $n=99$ & SQCC, $n=95$ & SCLC, $n=108$ & $p$-value & $\begin{array}{l}\text { p-value, } \\
\text { ADC vs } \\
\text { sQCC }^{a}\end{array}$ & $\begin{array}{l}\text { p-value, } \\
\text { ADC vs } \\
\text { sCLC }^{a}\end{array}$ & $\begin{array}{l}p \text {-value, } \\
\text { SQCC vs } \\
\text { SCLC }\end{array}$ \\
\hline $\mathrm{Age}^{\mathrm{b}}$ & $59(36-8 I)$ & $63(43-80)$ & $62(37-87)$ & 0.005 & 0.002 & 0.012 & 0.543 \\
\hline Sex & & & & $<0.001$ & $<0.001$ & $<0.001$ & $<0.001$ \\
\hline Male & 44 & 90 & 79 & & & & \\
\hline Female & 55 & 5 & 29 & & & & \\
\hline Smoking status & & & & $<0.001$ & $<0.001$ & $<0.001$ & $<0.001$ \\
\hline Smoker & 31 & 84 & 69 & & & & \\
\hline Nonsmoker & 68 & II & 39 & & & & \\
\hline $\mathrm{CEA}^{\mathrm{b}}(\mathrm{ng} / \mathrm{mL})$ & $17.10(0.28-595.2)$ & $3.37(0.7 I-58.09)$ & $3.23(0.32-167.5)$ & $<0.001$ & $<0.001$ & $<0.001$ & 0.90 \\
\hline Cyfra2I-Ib (ng/mL) & 6.08 (1.56-84.82) & $6.67(1.29-166.8)$ & $3.68(0.85-48.34)$ & $<0.001$ & 0.54 & $<0.001$ & $<0.001$ \\
\hline $\mathrm{NSE}^{\mathrm{b}}(\mathrm{ng} / \mathrm{mL})$ & I $7.52(4.42-367.3)$ & I 6.02 (8.44-74.77) & $51.31(9.74-508.00)$ & $<0.001$ & 0.16 & $<0.001$ & $<0.001$ \\
\hline
\end{tabular}

Notes: ${ }^{a}$ Bonferroni correction in which $p<0.0167$ is significant. ${ }^{b}$ Continuous quantitative data are presented as median and range.

Abbreviations: ADC, adenocarcinoma; CEA, carcinoembryonic antigen; Cyfra2I-I, cytokeratin 19 fragment; NSE, neuron-specific enolase; SCLC, small cell lung cancer; SQCC, squamous cell carcinoma.

\section{Multivariate analyses of pathologic types}

Table 4 shows the clinical and radiological characteristics that independently discriminated SQCC and SCLC from ADC via multivariate analysis. Compared with central SQCC, female sex, younger age, no history of smoking, higher levels of CEA and contralateral hilum lymphadenopathy were found to be the significantly independent indicators of central pulmonary ADC on multivariate logistic regression analysis. Also, compared with central SCLC, younger age, higher levels of CEA and Cyfra21-1, lower levels of NSE, presence of pleural nodules and lack of vascular involvement were significantly and independently associated with central ADC.

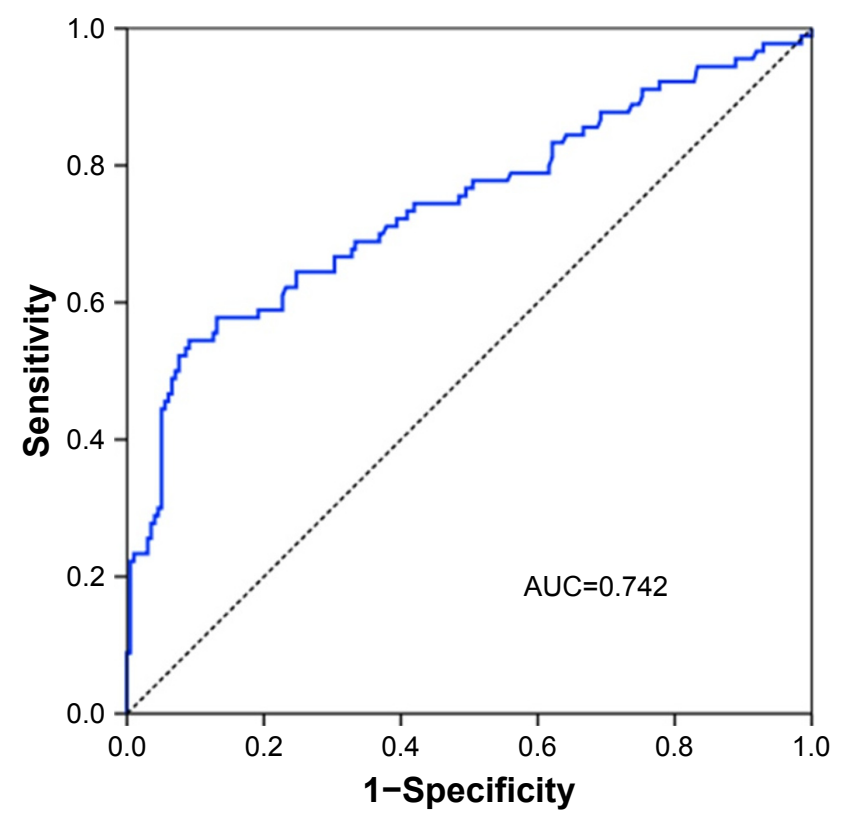

Figure I A receiver operating curve of the levels of CEA.

Abbreviations: AUC, area under the curve; CEA, carcinoembryonic antigen.

\section{The association between radiological characteristics of ADC and treatment response}

Among all patients with central ADC who received first-line platinum-based chemotherapy, the presence of pulmonary emphysema on the CT image was the only radiological feature that was significantly correlated with treatment response (Table 5). Multivariate logistic analysis revealed that the presence of pulmonary emphysema was correlated with a significantly poorer treatment response (odds ratio $=8.04$, 95\% CI 1.39-46.37, $p=0.02$ ) independent of age, sex, smoking status and tumor stage.

\section{Discussion}

In this study, we described the clinical and radiological characteristics of central pulmonary ADCs, compared them with those of patients with central SQCCs or SCLCs and correlated these features with the treatment response to first-line chemotherapy. Comparisons between central ADC and the other two pathologic types revealed distinct clinical and radiological profiles of central ADC. The presence of pulmonary emphysema was the only CT feature found to be an independent indicator of poorer treatment response to first-line chemotherapy in patients with central ADC.

With the increasing incidence of lung ADC, ADC has become the most common pathologic type of lung cancer worldwide. ${ }^{22}$ This may explain why the incidence of ADC in our study was similar to that of SQCC and SCLC among all central-type lung cancers, which is different from our previous understanding. There have been several studies on the radiological characteristics and prognoses of central SCLCs and SQCCs, ${ }^{5,12-15}$ whereas studies on the clinical 
Table 3 Associations between CT morphologic features and pathologic types

\begin{tabular}{|c|c|c|c|c|c|c|c|}
\hline Characteristics & $\begin{array}{l}\text { ADC, } \\
n=99\end{array}$ & $\begin{array}{l}\text { SQCC, } \\
n=95\end{array}$ & $\begin{array}{l}\text { SCLC, } \\
n=108\end{array}$ & $p$-value & $\begin{array}{l}\text { p-value, } \\
\text { ADC vs } \\
\text { sQCC }^{a}\end{array}$ & $\begin{array}{l}\text { p-value, } \\
\text { ADC vs } \\
\text { SCLC }^{a}\end{array}$ & $\begin{array}{l}p \text {-value, } \\
\text { SQCC vs } \\
\text { SCLC }\end{array}$ \\
\hline Maximal lesion size ${ }^{\mathrm{b}}(\mathrm{cm})$ & $4.7(2.4-13.9)$ & $4.7(I .4-11 . I)$ & $5.7(3.1-17.5)$ & 0.001 & 0.77 & 0.003 & 0.001 \\
\hline Location & & & & 0.86 & - & - & - \\
\hline Left & 47 & 49 & 55 & & & & \\
\hline Right & 52 & 46 & 53 & & & & \\
\hline Lobulated margin & 25 & 20 & 33 & 0.32 & - & - & - \\
\hline Spiculated margin & 20 & 22 & 11 & 0.04 & 0.73 & 0.05 & 0.01 \\
\hline Air bronchogram & 9 & 3 & I & $0.02^{c}$ & 0.13 & $0.008^{c}$ & $0.34^{c}$ \\
\hline Bronchovascular bundle convergence & 13 & 7 & 1 & 0.002 & 0.24 & $<0.001$ & $0.03^{c}$ \\
\hline Pulmonary infarction & 7 & 4 & 38 & $<0.001$ & 0.54 & $<0.001$ & $<0.001$ \\
\hline Lymphangitic carcinomatosis & 9 & I & 7 & $0.03^{c}$ & $0.02^{c}$ & 0.61 & $0.07^{c}$ \\
\hline Pulmonary emphysema & 12 & 29 & 23 & 0.007 & 0.003 & 0.10 & 0.15 \\
\hline Mediastinal lymphadenopathy & 82 & 62 & 84 & 0.01 & 0.006 & 0.39 & 0.06 \\
\hline Contralateral hilum lymphadenopathy & 23 & 3 & 9 & $<0.001$ & $<0.001$ & 0.004 & 0.14 \\
\hline Ipsilateral hilum lymphadenopathy & 71 & 57 & 76 & 0.16 & - & - & - \\
\hline Contralateral lung metastasis & 29 & 6 & 4 & $<0.001$ & $<0.001$ & $<0.001$ & $0.52^{c}$ \\
\hline Pleural nodules & 37 & 5 & 12 & $<0.001$ & $<0.001$ & $<0.001$ & 0.20 \\
\hline Interlobular fissure pleural metastasis & 17 & 0 & 2 & $<0.001$ & $<0.001$ & $<0.001$ & $0.50^{c}$ \\
\hline Pleural effusion & 55 & 24 & 46 & $<0.001$ & $<0.001$ & 0.07 & 0.01 \\
\hline Vascular involvement & 32 & 39 & 83 & $<0.001$ & 0.23 & $<0.001$ & $<0.001$ \\
\hline
\end{tabular}

Notes: aBonferroni correction in which $p<0.0167$ is significant. ${ }^{b}$ Continuous quantitative data are presented as median and range. 'Fisher's exact test.

Abbreviations: ADC, adenocarcinoma; CT, computed tomography; SCLC, small cell lung cancer; SQCC, squamous cell carcinoma.

and radiological characteristics of central ADCs and their correlation with patients' outcomes are rare. By investigating the clinical and radiological characteristics of different pathologic types of central lung cancers, we can further understand their distinct biological behaviors and the impact they have on treatment response, allowing for the application of individualized therapeutic strategies..$^{5,15}$

Our results revealed that patients with central ADC were more likely to be female, be of younger age, have never smoked or have higher levels of CEA (Table 2).
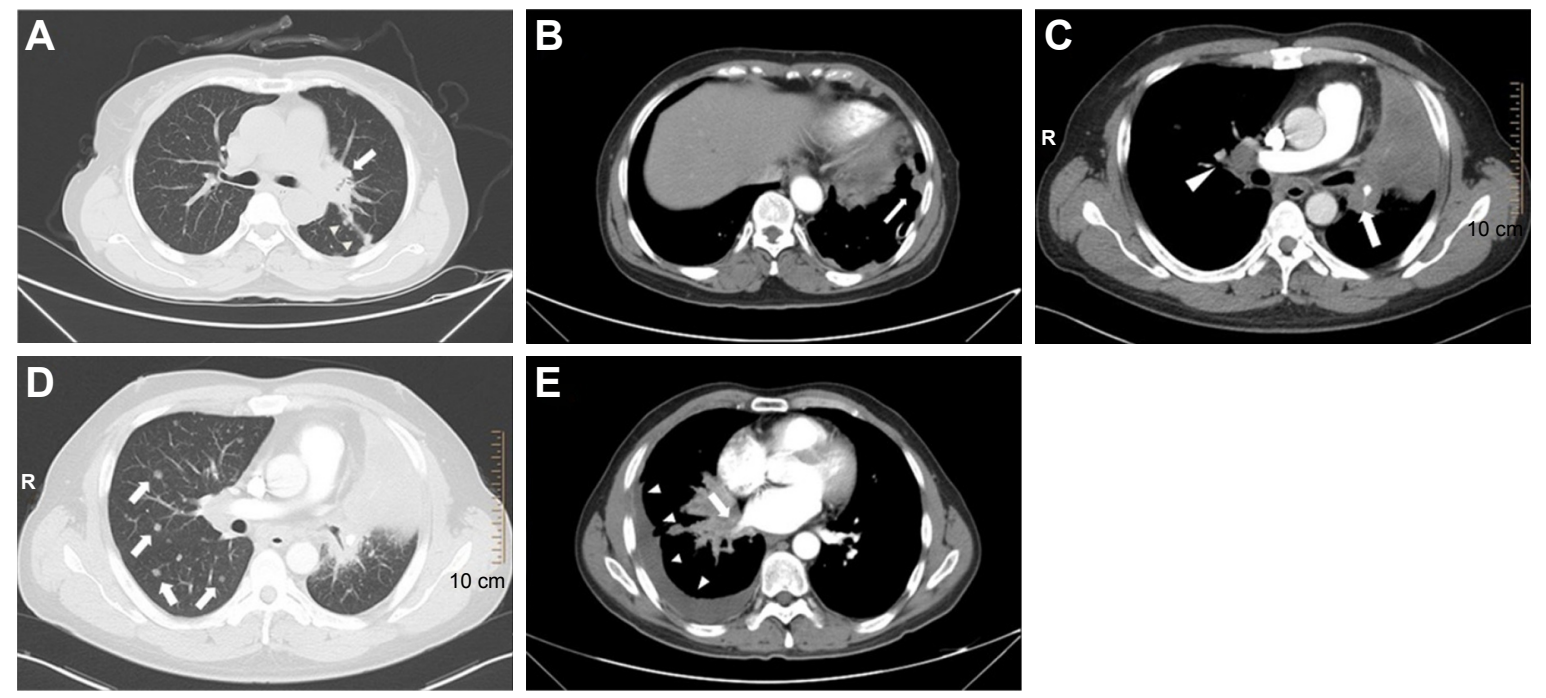

Figure 2 Representative CT images of central ADC.

Notes: A 6I-year-old female presented with (A) a primary lesion of central ADC in the left lung (arrow) with interlobular fissure pleural metastasis (arrowheads) and (B) a pleural nodule of left parietal pleura (arrow). A 43-year-old male presented with (C) a primary lesion of central ADC in the left lung with distal pulmonary atelectasis (arrow), contralateral hilum lymphadenopathy (arrowhead) and (D) contralateral lung metastasis (arrows). A 54-year-old male presented with (E) a primary lesion of central ADC in the right lung with involvement of right inferior pulmonary vein (arrow) and pleural effusion (arrowheads).

Abbreviations: ADC, adenocarcinoma; CT, computed tomography. 
Table 4 Clinical and radiological characteristics discriminating SQCC and SCLC from ADC in central lung adenocarcinoma via multivariate logistic regression analysis

\begin{tabular}{|c|c|c|c|c|}
\hline \multirow[t]{2}{*}{ Characteristics } & \multicolumn{2}{|l|}{ SQCC vs ADC } & \multicolumn{2}{|l|}{ SCLC vs ADC } \\
\hline & OR (95\% Cl) & $p$-value & OR (95\% CI) & $p$-value \\
\hline Age & $1.06(1.00-1.11)$ & 0.03 & $1.07(1.01-1.12)$ & 0.01 \\
\hline \multicolumn{5}{|l|}{ Sex } \\
\hline Male & $5.44(1.33-22.24)$ & 0.02 & $2.16(0.53-8.90)$ & 0.29 \\
\hline Female & Reference & & Reference & \\
\hline \multicolumn{5}{|l|}{ Smoking status } \\
\hline Nonsmoker & $0.18(0.05-0.64)$ & 0.01 & $0.42(0.11-1.65)$ & 0.21 \\
\hline Smoker & Reference & & Reference & \\
\hline CEA & $0.94(0.90-0.98)$ & 0.002 & $0.98(0.96-1.00)$ & 0.02 \\
\hline Cyfra2I-I & $1.03(1.00-1.07)$ & 0.07 & $0.56(0.45-0.70)$ & $<0.001$ \\
\hline NSE & $0.95(0.91-0.98)$ & 0.06 & $1.04(1.02-1.06)$ & $<0.001$ \\
\hline Maximal lesion size & $0.83(0.63-1.10)$ & 0.19 & $1.23(0.90-1.68)$ & 0.19 \\
\hline \multicolumn{5}{|l|}{ Pulmonary infarction } \\
\hline No & 4.11 (0.72-23.43) & 0.11 & $0.76(0.19-3.05)$ & 0.69 \\
\hline Yes & Reference & & Reference & \\
\hline \multicolumn{5}{|c|}{ Contralateral hilum lymphadenopathy } \\
\hline No & $8.85(1.28-61.04)$ & 0.03 & $1.14(0.21-6.27)$ & 0.88 \\
\hline Yes & Reference & & Reference & \\
\hline \multicolumn{5}{|l|}{ Pleural nodules } \\
\hline No & $3.87(0.86-17.44)$ & 0.08 & $4.57(1.27-16.38)$ & 0.02 \\
\hline Yes & Reference & & Reference & \\
\hline \multicolumn{5}{|l|}{ Vascular involvement } \\
\hline No & $0.69(0.38-1.23)$ & 0.21 & $0.12(0.04-0.36)$ & $<0.001$ \\
\hline Yes & Reference & & Reference & \\
\hline
\end{tabular}

Abbreviations: ADC, adenocarcinoma; CEA, carcinoembryonic antigen; Cyfra2I-I, cytokeratin 19 fragment; NSE, neuron-specific enolase; OR, odds ratio; SCLC, small cell lung cancer; SQCC, squamous cell carcinoma.

The presence of pleural effusion $(n=55 / 99,55.56 \%)$ and the presence of vascular involvement $(n=32 / 99,32.32 \%)$ were the common CT findings of central ADCs (Table 3 ). More importantly, we found that central ADCs presented more commonly with contralateral hilum lymphadenopathy, contralateral lung metastasis, pleural nodules and interlobular fissure pleural metastasis (Table 3) compared to the other two pathologic types. Meanwhile, contralateral hilum lymphadenopathy and pleural nodules were two independent radiological indicators for central ADC (Table 4). The distinctive clinical and radiological features of central ADCs may provide an auxiliary and noninvasive method for differential diagnosis.

There have been several studies comparing the clinical and radiological features among different pathologic types of lung cancers. Koenigkam Santos et $\mathrm{al}^{5}$ found that compared to ADC, SQCC lesions were more central and less peripheral (43\% for central SQCC vs 23\% for ADC). In addition, SQCC presented a higher proportion of men, a higher age and less associated pleural tags, but no difference in lesion's diameter was found, which is consistent with the results of our study (Table 3). Furthermore, Koenigkam Santos et al also demonstrated that SQCCs showed less spiculated and more lobulated margins, and less commonly presented with internal air bronchogram compared to ADCs. These differences were also significant when comparing only peripheral lesions. However, in our study, no significant differences in these three CT signs were identified between patients with central ADC and SQCC (Table 3). More than half of the patients in the study by Koenigkam Santos et al had peripheral lung cancer, which may explain the differences in the results. Smith et $\mathrm{al}^{6}$ found that the presence of emphysema was associated with SQCC (adjusted odds ratio 2.6, 95\% CI 1.4-4.8) rather than ADC and SCLC after adjustment for age, sex, COPD and smoking history. The univariate analysis in our study also showed that SQCCs presented more commonly with emphysema compared to the other two pathologic types, but only the comparison with ADC was statistically significant. The study by Ren et al aimed to distinguish peripheral SCLCs (PSCLCs) from peripheral NSCLCs (PNSCLCs) using CT imaging ${ }^{23}$ and found that there was no difference between PSCLCs and PNSCLCs in lesion size, and presence of air bronchogram and pleural effusion, but PNSCLCs presented with more spiculated signs and bronchovascular convergence signs. In our study, central NSCLCs comprised ADCs and SQCCs. 
Table 5 Associations of clinical and CT features with treatment response of central ADC using univariate and multivariate logistic regression models

\begin{tabular}{|c|c|c|c|c|c|c|}
\hline \multirow[t]{2}{*}{ Characteristics } & \multirow{2}{*}{$\begin{array}{l}\text { Response group, } \\
\mathrm{n}=\mathbf{4 2}\end{array}$} & \multirow{2}{*}{$\begin{array}{l}\text { Nonresponse } \\
\text { group, } n=43\end{array}$} & \multicolumn{2}{|c|}{ Univariate analysis } & \multicolumn{2}{|c|}{ Multivariate analysis } \\
\hline & & & OR $(95 \% \mathrm{Cl})$ & $p$-value & OR $(95 \% \mathrm{CI})$ & $p$-value \\
\hline $\mathrm{Age}^{\mathrm{a}}$ & $59(38-79)$ & $58(36-8 I)$ & $1.01(0.97-1.06)$ & 0.57 & $1.03(0.97-1.08)$ & 0.34 \\
\hline \multicolumn{7}{|l|}{ Sex } \\
\hline Male & 18 & 20 & Reference & & - & - \\
\hline Female & 24 & 23 & $0.86(0.37-2.03)$ & 0.74 & $\mathrm{I} .5 \mathrm{I}(0.44-5.2 \mathrm{I})$ & 0.52 \\
\hline \multicolumn{7}{|l|}{ Smoking status } \\
\hline Nonsmoker & 30 & 28 & Reference & & - & - \\
\hline Smoker & 12 & 15 & $1.34(0.54-3.35)$ & 0.53 & $1.5 \mathrm{I}(0.40-5.6 \mathrm{I})$ & 0.54 \\
\hline \multicolumn{7}{|l|}{ Tumor stage } \\
\hline I-III & 24 & 18 & Reference & & - & - \\
\hline IV & 18 & 25 & $1.85(0.78-4.38)$ & 0.16 & $2.07(0.82-5.18)$ & 0.12 \\
\hline $\mathrm{CEA}^{\mathrm{a}}(\mathrm{ng} / \mathrm{mL})$ & $24.67(0.66-286.50)$ & $6.73(0.28-595.20)$ & $1.00(0.99-1.01)$ & 0.31 & - & - \\
\hline Cyfra2I-Ia $(\mathrm{ng} / \mathrm{mL})$ & $7.02(1.90-45.35)$ & $5.50(1.56-84.82)$ & $0.99(0.95-1.03)$ & 0.67 & - & - \\
\hline $\operatorname{NSE}^{a}(\mathrm{ng} / \mathrm{mL})$ & $20.50(4.42-61.54)$ & $17.11(11.09-367.30)$ & $1.00(0.98-1.01)$ & 0.50 & - & - \\
\hline Maximal lesion size $(\mathrm{cm})$ & $4.8(2.6-7.8)$ & $5.0(2.6-13.9)$ & $0.84(0.64-1.11)$ & 0.22 & - & - \\
\hline Location & & & & & - & - \\
\hline Left & 21 & 19 & Reference & & - & - \\
\hline Right & 21 & 24 & $1.26(0.54-2.97)$ & 0.59 & - & - \\
\hline Lobulated margin & 8 & 11 & $1.46(0.52-4.10)$ & 0.47 & - & - \\
\hline Spiculated margin & 8 & 8 & $0.97(0.33-2.88)$ & 0.96 & - & - \\
\hline Air bronchogram & 5 & 4 & $0.76(0.19-3.05)$ & 0.70 & - & - \\
\hline Bronchovascular bundle convergence & 6 & 5 & $0.79(0.22-2.82)$ & 0.72 & - & - \\
\hline Pulmonary infarction & 3 & 4 & $1.33(0.28-6.35)$ & 0.72 & - & - \\
\hline Lymphangitic carcinomatosis & 3 & 5 & I.7I (0.38-7.66) & 0.48 & - & - \\
\hline Pulmonary emphysema & 2 & 9 & $5.29(1.07-26.19)$ & 0.04 & $8.04(1.39-46.37)$ & 0.02 \\
\hline Ipsilateral hilum lymphadenopathy & 35 & 30 & $0.46(0.16-1.31)$ & 0.15 & - & - \\
\hline Contralateral hilum lymphadenopathy & 11 & 12 & $1.10(0.42-2.84)$ & 0.86 & - & - \\
\hline Mediastinal lymphadenopathy & 37 & 35 & $0.59(0.18-1.98)$ & 0.39 & - & - \\
\hline Contralateral lung metastasis & 16 & 10 & $0.49(0.19-1.26)$ & 0.14 & - & - \\
\hline Pleural nodules & 17 & 14 & $0.7 \mid(0.29-1.72)$ & 0.45 & - & - \\
\hline Interlobular fissure pleural metastasis & 7 & 9 & $1.32(0.44-3.96)$ & 0.61 & - & - \\
\hline Pleural effusion & 22 & 27 & $1.53(0.65-3.65)$ & 0.33 & - & - \\
\hline Vascular involvement & 12 & 15 & $1.34(0.54-3.35)$ & 0.53 & - & - \\
\hline
\end{tabular}

Note: aContinuous quantitative data are presented as median and range.

Abbreviations: ADC, adenocarcinoma; CEA, carcinoembryonic antigen; CT, computed tomography; Cyfra2I-I, cytokeratin 19 fragment; NSE, neuron-specific enolase; OR, odds ratio.

The results of comparisons among central ADC, SQCC and SCLC (Tables 3-5) were not identical to those of PNSCLC and PSCLC ${ }^{23}$ in both univariate analyses and multivariate analyses. This difference could be attributed to varying tumor characteristics, including the lesion location, the categories and the presence or absence of clinical variables. Therefore, it is necessary to differentiate central lung cancers from peripheral lung cancers.

Pulmonary emphysema is characterized pathologically by permanently enlarged airspaces distal to the terminal bronchiole with destruction of alveolar walls, and presents as focal areas or regions of low attenuation, usually without visible walls in $\mathrm{CT} .{ }^{20} \mathrm{In}$ fact, the prognostic role of emphysema in NSCLC has been proven in several studies. ${ }^{24-28}$ Gullon et al ${ }^{25}$ retrospectively reviewed 353 patients with cytohistologic diagnosis of NSCLC and showed that emphysema (hazard ratio $=1.49,95 \%$ CI $1.11-2.01$ ) was an independent prognostic factor. Although the presence of pulmonary emphysema was relatively infrequent in patients with central ADC compared to the other two groups (Table 3), its impact on therapeutic strategies and patients' outcome cannot be overlooked. Our findings suggested that the presence of pulmonary emphysema on $\mathrm{CT}$ imaging was an independent indicator of poorer treatment response to firstline chemotherapy in patients with central ADC (Table 5). On the one hand, recent studies have demonstrated that emphysema was associated with abnormal apoptosis and cell cycle regulation, ${ }^{29}$ which might lead to chemoresistance since regulation of apoptosis was the main mechanism of chemotherapy. On the other hand, epigenetic modifications were common in emphysema, ${ }^{30,31}$ which played a crucial role in chemoresistance of lung cancer. ${ }^{32,33}$ Moreover, the 
relationship between emphysema and prognosis suggested a more aggressive form of cancer in these patients, ${ }^{27}$ which might cause poor treatment response to chemotherapy. Besides, the presence of emphysema indicated a poorer physical condition, which limited the treatment options and might lead to lower tolerance to chemotherapy.

In general, the radiological features of central ADC in our study appeared to be aggressive, which might indicate poor prognosis. Studies have proven the relationship between prognosis and the features of ADCs on CT imaging, including the percentage of ground-glass opacity, ${ }^{10,34,35}$ pleural attachment, ${ }^{36,37}$ lymphadenopathy, ${ }^{36,37}$ lymphovascular invasion $^{19}$ and so on. Most of these studies did not distinguish central from peripheral ADCs. However, the prognosis of patients with central ADC was different from that of patients with peripheral ADC. ${ }^{16-19}$ Unlike previous studies, most patients in our study were at stage III or IV when they were diagnosed with central lung cancer (Table 1). The status of lymph node metastasis plays a critical role in predicting prognosis and determining therapeutic strategies in lung cancer. ${ }^{38}$ More than $70 \%$ of patients with central ADC in our study were diagnosed with mediastinal lymphadenopathy or hilum lymphadenopathy (Table 2). Recent studies ${ }^{16,17}$ have suggested that the prognosis of patients with central ADC is poorer compared with peripheral ADC, and central ADC is related to a greater rate of nodal metastasis even with a small lesion size. The mechanism underlying the poor prognosis of central ADC may be attributed to the pathologic lymphovascular invasion and other histologic changes. ${ }^{16,19}$ Moreover, it has been reported that the 5-year survival rates of patients with NSCLCs with pleural dissemination and separate malignant nodule in the contralateral lung are $2 \%$ and $3 \%$, respectively. ${ }^{39}$ In our study, $37.4 \%$ and $17.2 \%$ of patients with central ADC presented with pleural nodules and interlobular fissure pleural metastasis, respectively (Table 3), which might also contribute to poor prognosis of central ADC. In a future study, the authors hope to investigate the correlation between the radiological characteristics and the prognosis of patients with central ADCs.

Our study has several limitations. First, this was a retrospective study. Hence, there was a selection bias. In addition, molecular status, such as epidermal growth factor receptor and anaplastic lymphoma kinase, was not included in the analyses, which requires further detailed studies. Besides, the number of patients with some radiological features, such as pulmonary emphysema, interlobular fissure pleural metastasis and lymphangitic carcinomatosis, was limited, which might impair the statistical power of our study. Hence, a larger cohort is required.

\section{Conclusion}

Recent studies have revealed that adequate radiological characteristics of lung lesions play a critical role in inferring histologic subtypes, choosing optimal treatment and determining patients' prognosis. In conclusion, our study revealed the distinct clinical and radiological profiles of central pulmonary ADCs in comparison with central SCLCs and SQCCs and the impact of these tumor characteristics on treatment response. Our study may provide an auxiliary and noninvasive method for the differential diagnosis of central lung cancers through their clinical and radiological characteristics. More importantly, our results may be helpful to guide therapeutic strategies of central pulmonary ADC.

\section{Acknowledgments}

This work was supported by the grants from the National Health and Family Planning Commission of China (201402011), Shandong Key Research and Development Plan (2017CXGC1209 and 2017GSF18164) and Innovation Project of Shandong Academy of Medical Science.

\section{Disclosure}

The authors report no conflicts of interest in this work.

\section{References}

1. Ferlay J, Soerjomataram I, Dikshit R, et al. Cancer incidence and mortality worldwide: sources, methods and major patterns in GLOBOCAN 2012. Int J Cancer. 2015;136(5):E359-E386.

2. Perez-Moreno P, Brambilla E, Thomas R, Soria JC. Squamous cell carcinoma of the lung: molecular subtypes and therapeutic opportunities. Clin Cancer Res. 2012;18(9):2443-2451.

3. Katki HA, Kovalchik SA, Berg CD, Cheung LC, Chaturvedi AK. Development and validation of risk models to select ever-smokers for CT lung cancer screening. JAMA. 2016;315(21):2300-2311.

4. Black WC, Gareen IF, Soneji SS, et al; National Lung Screening Trial Research Team. Cost-effectiveness of CT screening in the National Lung Screening Trial. N Engl J Med. 2014;371(19):1793-1802.

5. Koenigkam Santos M, Muley T, Warth A, et al. Morphological computed tomography features of surgically resectable pulmonary squamous cell carcinomas: impact on prognosis and comparison with adenocarcinomas. Eur J Radiol. 2014;83(7):1275-1281.

6. Smith BM, Schwartzman K, Kovacina B, et al. Lung cancer histologies associated with emphysema on computed tomography. Lung Cancer. 2012;76(1):61-66.

7. Kunihiro Y, Kobayashi T, Tanaka N, et al. High-resolution CT findings of primary lung cancer with cavitation: a comparison between adenocarcinoma and squamous cell carcinoma. Clin Radiol. 2016;71(11): 1126-1131.

8. Wakatsuki K, Matsumoto S, Migita K, et al. Usefulness of computed tomography density of a tumor in predicting the response of advanced esophageal cancer to preoperative chemotherapy. Surgery. 2017;162(4): 823-835.

9. Kim YS, Kim EY, Ahn HK, Cho EK, Jeong YM, Kim JH. Prognostic significance of CT-emphysema score in patients with advanced squamous cell lung cancer. J Thorac Dis. 2016;8(8):1966-1973.

10. Yamazaki M, Ishikawa $H$, Kunii R, et al. A combination of preoperative $\mathrm{CT}$ findings and postoperative serum CEA levels improves recurrence prediction for stage I lung adenocarcinoma. Eur J Radiol. 2015;84(1):178-184. 
11. Wang H, Schabath MB, Liu Y, et al. Semiquantitative computed tomography characteristics for lung adenocarcinoma and their association with lung cancer survival. Clin Lung Cancer. 2015;16(6):e141-e163.

12. Li Q, Fan X, Huang XT, et al. Tree-in-bud pattern in central lung cancer: CT findings and pathologic correlation. Lung Cancer. 2015;88(3): 260-266.

13. Lee D, Rho JY, Kang S, Yoo KJ, Choi HJ. CT findings of small cell lung carcinoma: can recognizable features be found? Medicine (Baltimore). 2016;95(47):e5426.

14. Hayashi T, Sano H, Egashira R, et al. Difference of morphology and immunophenotype between central and peripheral squamous cell carcinomas of the lung. Biomed Res Int. 2013;2013:157838.

15. Miyauchi E, Motoi N, Ono H, et al. Distinct characteristics of small cell lung cancer correlate with central or peripheral origin: subtyping based on location and expression of transcription factor TTF-1. Medicine (Baltimore). 2015;94(51):e2324.

16. Sun W, Yang X, Liu Y, Yuan Y, Lin D. Primary tumor location is a useful predictor for lymph node metastasis and prognosis in lung adenocarcinoma. Clin Lung Cancer. 2017;18(1):e49-e55.

17. Ketchedjian A, Daly BD, Fernando HC, et al. Location as an important predictor of lymph node involvement for pulmonary adenocarcinoma. J Thorac Cardiovasc Surg. 2006;132(3):544-548.

18. Ito M, Yamashita Y, Miyata Y, et al. Prognostic impact of the primary tumor location based on the hilar structures in non-small cell lung cancer with mediastinal lymph node metastasis. Lung Cancer. 2012;76(1): 93-97.

19. Koo HJ, Xu H, Choi CM, et al. Preoperative CT predicting recurrence of surgically resected adenocarcinoma of the lung. Medicine (Baltimore). 2016;95(2):e2513.

20. Hansell DM, Bankier AA, MacMahon H, McLoud TC, Muller NL, Remy J. Fleischner society: glossary of terms for thoracic imaging. Radiology. 2008;246(3):697-722.

21. Shim SS, Lee KS, Kim BT, et al. Integrated PET/CT and the dry pleural dissemination of peripheral adenocarcinoma of the lung: diagnostic implications. J Comput Assist Tomogr. 2006;30(1):70-76.

22. Travis WD, Brambilla E, Noguchi M, et al; American Thoracic Society. International association for the study of lung cancer/American thoracic society/European respiratory society: international multidisciplinary classification of lung adenocarcinoma: executive summary. Proc Am Thorac Soc. 2011;8(5):381-385.

23. Ren Y, Cao Y, Hu W, Wei X, Shen X. Diagnostic accuracy of computed tomography imaging for the detection of differences between peripheral small cell lung cancer and peripheral non-small cell lung cancer. Int J Clin Oncol. 2017;22(5):865-871.

24. Gao YH, Guan WJ, Liu Q, et al. Impact of COPD and emphysema on survival of patients with lung cancer: a meta-analysis of observational studies. Respirology. 2016;21(2):269-279.
25. Gullon JA, Suarez I, Medina A, Rubinos G, Fernandez R, Gonzalez I Role of emphysema and airway obstruction in prognosis of lung cancer. Lung Cancer. 2011;71(2):182-185.

26. Ueda K, Jinbo M, Li TS, Yagi T, Suga K, Hamano K. Computed tomography-diagnosed emphysema, not airway obstruction, is associated with the prognostic outcome of early-stage lung cancer. Clin Cancer Res. 2006;12(22):6730-6736.

27. Murakami J, Ueda K, Sano F, Hayashi M, Nishimoto A, Hamano K. Pulmonary emphysema and tumor microenvironment in primary lung cancer. J Surg Res. 2016;200(2):690-697.

28. Girard N, Marchand-Adam S, Naccache JM, et al; Groupe d'Etudes et de Recherche sur les Maladies “Orphelines” Pulmonaires (GERM“O”P). Lung cancer in combined pulmonary fibrosis and emphysema: a series of 47 Western patients. J Thorac Oncol. 2014;9(8):1162-1170.

29. Demedts IK, Demoor T, Bracke KR, Joos GF, Brusselle GG. Role of apoptosis in the pathogenesis of COPD and pulmonary emphysema. Respir Res. 2006;7:53.

30. Liloglou T, Bediaga NG, Brown BR, Field JK, Davies MP. Epigenetic biomarkers in lung cancer. Cancer Lett. 2014;342(2):200-212.

31. Qiu W, Baccarelli A, Carey VJ, et al. Variable DNA methylation is associated with chronic obstructive pulmonary disease and lung function. Am J Respir Crit Care Med. 2012;185(4):373-381.

32. Rosell R, Cecere F, Santarpia M, Reguart N, Taron M. Predicting the outcome of chemotherapy for lung cancer. Curr Opin Pharmacol. 2006; 6(4):323-331.

33. Tao L, Huang G, Chen Y, Chen L. DNA methylation of DKK3 modulates docetaxel chemoresistance in human nonsmall cell lung cancer cell. Cancer Biother Radiopharm. 2015;30(2):100-106.

34. Moon Y, Sung SW, Lee KY, Park JK. Clinicopathological characteristics and prognosis of non-lepidic invasive adenocarcinoma presenting as ground glass opacity nodule. J Thorac Dis. 2016;8(9):2562-2570.

35. Nawa T, Nakagawa T, Mizoue T, et al. Long-term prognosis of patients with lung cancer detected on low-dose chest computed tomography screening. Lung Cancer. 2012;75(2):197-202.

36. Ma J, Yang YL, Wang Y, Zhang XW, Gu XS, Wang ZC. Relationship between computed tomography morphology and prognosis of patients with stage I non-small cell lung cancer. Onco Targets Ther. 2017;10: 2249-2256.

37. Wang H, Schabath MB, Liu Y, et al. Semiquantitative computed tomographic characteristics for lung adenocarcinoma and their association with lung cancer survival. Clin Lung Cancer. 2015;16(6):e141-e163.

38. Rusch VW, Crowley J, Giroux DJ, et al. The IASLC lung cancer staging project: proposals for the revision of the $\mathrm{N}$ descriptors in the forthcoming seventh edition of the TNM classification for lung cancer. $J$ Thorac Oncol. 2007;2(7):603-612.

39. Detterbeck FC, Boffa DJ, Tanoue LT. The new lung cancer staging system. Chest. 2009;136(1):260-271.
OncoTargets and Therapy

\section{Publish your work in this journal}

OncoTargets and Therapy is an international, peer-reviewed, open access journal focusing on the pathological basis of all cancers, potential targets for therapy and treatment protocols employed to improve the management of cancer patients. The journal also focuses on the impact of management programs and new therapeutic agents and protocols on

\section{Dovepress}

patient perspectives such as quality of life, adherence and satisfaction. The manuscript management system is completely online and includes a very quick and fair peer-review system, which is all easy to use. Visit http://www.dovepress.com/testimonials.php to read real quotes from published authors. 